\title{
Electrochemical Behavior of Acid Orange 7 by Cyclic Voltammetry in Different Solvents
}

\author{
Rawdha Ennouri, ${ }^{a}$ Marco Panizza,,${ }^{b *}$ Tahar Mhiri, ${ }^{a}$ and Sourour C. Elaoud ${ }^{a}$ \\ ${ }^{a}$ Laboratoire de Physico-Chimie de l'Etat Solide, Département de Chimie, Faculté des Sciences \\ de Sfax, 3000 Université de Sfax, Sfax, Tunisie \\ ${ }^{b}$ Department of Chemical and Process Engineering, University of Genoa, P. le J. F. Kennedy 1 , \\ 16129 Genova, Italy
}

Received September 29, 2016; accepted January 8, 2017

\begin{abstract}
In the present work, the electrochemical oxidation of acid orange 7 (AO7) on a glassy carbon (GC) electrode has been investigated by cyclic voltammetry in different solvents: aqueous solvent $\left(\mathrm{H}_{2} \mathrm{O}\right)$, dimethyl sulfoxide (DMSO) and acetone (ACE), using sulfuric acid as a supporting electrolyte. The analysis of AO7 oxidation voltammograms in different solvents showed that the more donor numbers, the easier it becomes the oxidation of AO7. The experimental parameters show that the oxidation peak current of AO7 was linearly proportional to its concentration in a range from $0.04 \mathrm{mM}$ to $0.2 \mathrm{mM}$. The limit of detection was estimated by gradually decreasing the concentration levels of $\mathrm{AO} 7$, and was found to be $6.6 \mu \mathrm{M}$.
\end{abstract}

Keywords: Azo dye; cyclic voltammetry; glassy carbon electrode; solvent effect; donor number.

\section{Introduction}

Aromatic azo compounds constitute a very important class of organic compounds, because of their widespread applications in many fields of up-todate technology, involving textile industry, leather tanning industry, paper production, food processing, and agricultural research [1]. Among them, the aromatic azo dyes $(-\mathrm{N}=\mathrm{N}-)$ comprise about two-thirds of the total [2].

The majority of these compounds are carcinogenic. In fact, many synthetic azo dyes can be converted to colorless aromatic amines. Azo dyes are generally biodegraded by azo-bond reduction during anaerobic digestion, which generates aromatic amines [3, 4], leading to the need of sensitive analytical methods for their determination.

\footnotetext{
* Corresponding author. E-mail address: marco.panizza@unige.it
} 
To date, many methods have been investigated for the determination of azo dyes, such as polarographic and voltammetric methods, which are particularly suitable for these purposes, because of their high sensitivity, their applicability over an unusually wide concentration range, and their low investment and running costs [1-10]. There are other methods for the quantitative detection and characterization of azo dyes, including electronic spectroscopy [11], infrared spectroscopy [12-14], mass spectroscopy [15, 16], gas chromatography/mass spectroscopy, high-performance liquid chromatography (HPLC) with UV-Vis and mass detectors [17-23].

It is well known that electrochemical methods are the most widely used in direct determination of chemical molecules, as they are not only rapid and sensitive, but also more feasible for microanalysis.

Cyclic voltammetry is a very versatile electrochemical technique in modern analytical chemistry for the characterization of electroactive species. This method provides valuable information regarding the stability of the oxidation states and the rate of electron transfer between the electrode and the analyte. This technique is accomplished with a three-electrode arrangement: the potential is applied to the working electrode with respect to a reference electrode, while an auxiliary (or counter) electrode is used to complete the electrical circuit [24].

For these reasons, the electrochemical detection of dyes has attracted the attention of many authors [25-27]. Some of them have studied the voltammetric analysis of reactive dyes by oxidation of their oxidizable or reduction of their reductable groups present in the dye molecule [27]. Others tried to change the mercury electrode, because of its toxicity, by glassy carbon electrode. Gold and boron-doped diamond have been efficiently used for the electroanalytical detection of some organic compounds in aqueous solutions, but only few studies have been conducted in non-aqueous electrolytes.

In the present work, the electrochemical behavior of acid orange 7 (OA7), chosen as model azo dye, was studied at glassy carbon electrode in different electrolytes. Solvent effects on the redox properties of radicals and radical ions have been subject of considerable interest [28-33]. The solvent effect on the redox potential is interpreted based on the strength of interactions involving both the cation $\mathrm{Na}^{+}$ and solvent molecules, and is influenced by the donor properties (and thus the donor number) of the solvent medium.

\section{Materials and methods \\ Chemicals}

The molecular structure of the azo dyes acid orange 7 is given in Fig. 1.

Acid orange 7 (Sigma Aldrich) was used as received. The studied organic solvents were dimetyl sulfoxide (DMSO) and acetone (ACE), and the supporting electrolyte was sulfuric acid.

\section{Solutions}

A concentrated solution $(0.50 \mathrm{~mol} / \mathrm{L})$ of the supporting electrolyte sulfuric acid in each appropriate solvent was used for the preparation of the solutions $\left(2.10^{-4}\right.$ 
$\mathrm{mol} / \mathrm{L}$ ) of acid orange 7 . Under the conditions used in this work, the AO7 was completely soluble in all of the investigated solvents.

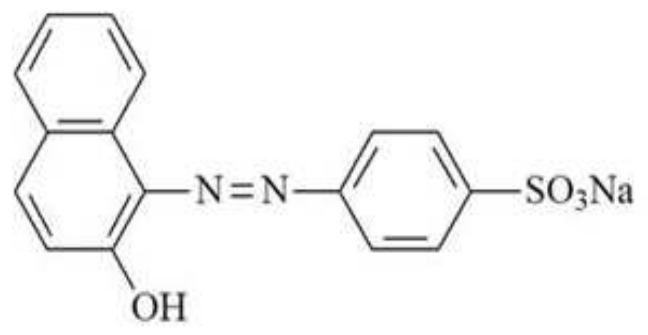

Figure 1. Molecular structure of acid orange 7.

\section{Cyclic voltammetry}

The measurements were carried out using a potentiostat/galvanostat type VoltaLab PST 050 "(Radiometer Analytical). A conventional three-electrode system with one compartment cell was used for all the measurements, using glassy carbon (GC, $3.0 \mathrm{~mm}$ diameter) and $\mathrm{Ag} / \mathrm{AgCl}$ as reference electrode, and a stainless steel bar as an auxiliary electrode. The working GC electrode was polished with alumina powder, followed by washing with water and acetone before each cyclic voltammogram.

\section{Results and discussion}

\section{Electrochemical behavior of acid orange 7 in different solvents}

Fig. 2 shows a series of cyclic voltammograms recorded in the presence of AO7 $2.10^{-4} \mathrm{M}$ at a glassy carbon electrode in various solvents: water, acetone (ACE), and dimethyl sulfoxide (DMSO) at $20{ }^{\circ} \mathrm{C}$ using $\mathrm{H}_{2} \mathrm{SO}_{4} 0.5 \mathrm{M}$ as supporting electrolyte.

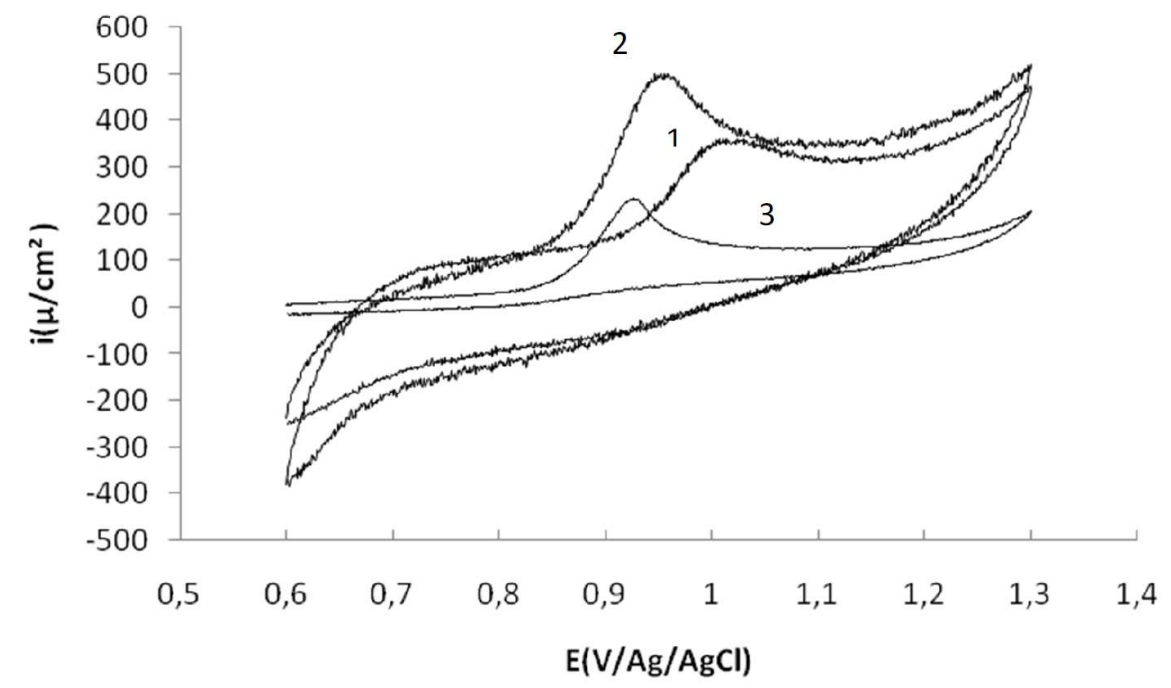

Figure 2. Cyclic voltammograms of $\mathrm{AO} 72 \cdot 10^{-4} \mathrm{M}$ at a $\mathrm{GC}$ electrode in different solvent medium. The curves are denoted as follows: DMSO (1), water (2), and ACE (3).

The analysis of this figure shows that the oxidation peak potentials of $\mathrm{AO} 7$ in these three different solvents are different: $\left(\mathrm{DMSO}: \mathrm{E}_{\mathrm{Pa}}=0.92 \mathrm{~V}\right.$, water: $\mathrm{E}_{\mathrm{Pa}}=$ 
$0.95 \mathrm{~V}$; acetone: $\mathrm{E}_{\mathrm{Pa}}=1 \mathrm{~V}$ ). These results can be explained based on the number of donors relative to these three solvents (Table 1) [34]. Indeed, the number of donors measures the alkalinity or the donation ability of a solvent.

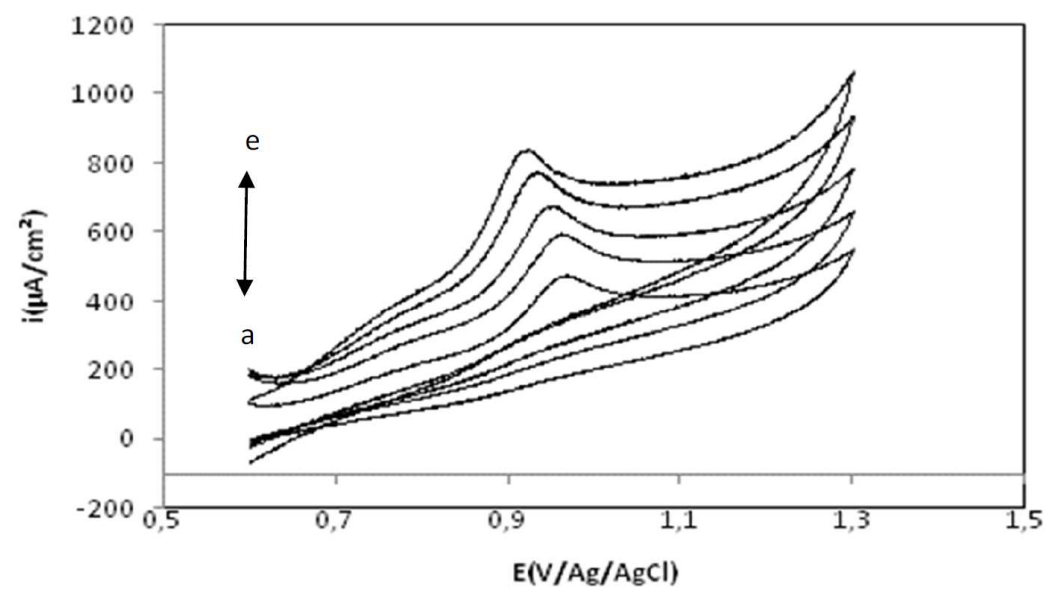

a)

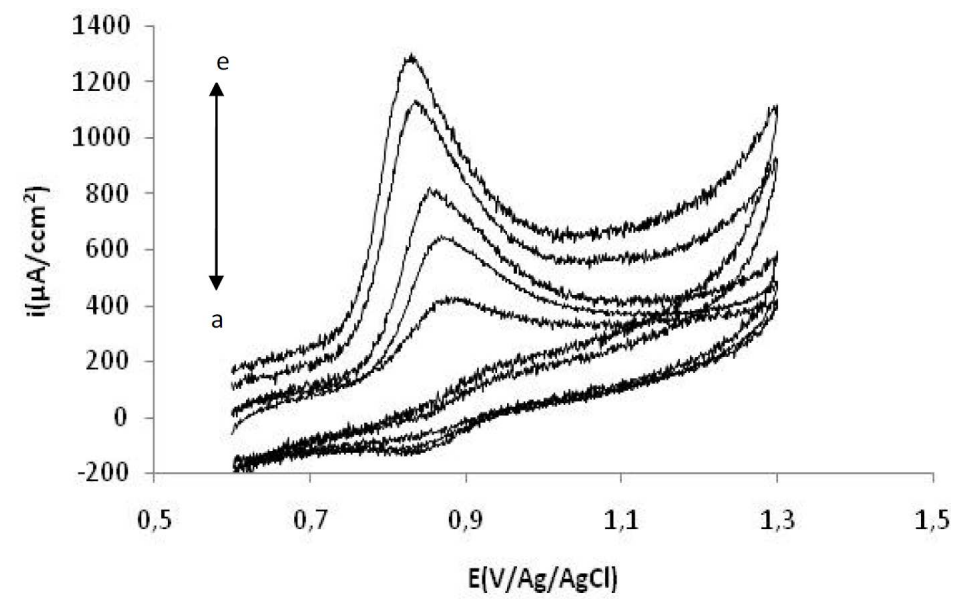

b)

Figure 3. a) Cyclic voltammetry of $2 \cdot 10^{-4} \mathrm{M}$ AO7 at GCE in $0.5 \mathrm{M} \mathrm{H}_{2} \mathrm{SO}_{4}$ at various temperatures from $20{ }^{\circ} \mathrm{C}$ to $60{ }^{\circ} \mathrm{C}$ (a-e) in DMSO; b) Cyclic voltammetry of $2.10^{-4} \mathrm{M}$ $\mathrm{AO} 7$ at $\mathrm{GCE}$ in $0.5 \mathrm{M} \mathrm{H}_{2} \mathrm{SO}_{4}$ at various temperatures from $20{ }^{\circ} \mathrm{C}$ to $60{ }^{\circ} \mathrm{C}$ (a-e) in aqueous media.

The examination of Table 1 indicates that the oxidation of AO7 becomes more difficult on going from DMSO to ACE [35, 36]. The shift of $E^{\circ}$ can be explained by donor-acceptor Lewis-type interactions [37]. In fact, as DMSO presents the largest number of donors, it is richer in electrons and, consequently, solvates better $\mathrm{AO7}$. On the other hand, the strength of interactions involve the $\mathrm{Na}^{+}$cation (which acts as a Lewis electron-pair acceptor) in the structure of AO7, which is more sensitive to interactions with the solvent molecules (DMSO), that act as a Lewis electron-pair donor. Consequently, a strong electron contribution of the solvent molecule acts as an electron donor to the cation $\mathrm{Na}^{+}$, which leads to a diminution of the $\mathrm{E}^{\circ}$ value, thereafter making oxidation easier in this case, which manifests itself by a shift of the oxidation peak potential to the more cathodic potentials; this behavior is summarized in Table 1, which represents the evolution of the oxidation potentials of $\mathrm{AO}$, depending on the number of donors of the different solvents. 
Table 1. Number of donors relative to the three solvents.

\begin{tabular}{|c|c|c|}
\hline Solvent & Number of donors & Oxidation potential (V) \\
\hline DMSO & 29.8 & 0.92 \\
\hline Water & 18 & 0.95 \\
\hline Acetone & 17 & 1 \\
\hline
\end{tabular}

To better demonstrate the benefits of the use of DMSO as a solvent we have studied the influence of temperature on the oxidation of AO7 by a comparative study using two solvents: DMSO and water. We have recapitulated the results obtained in Figs. 3 (a-b) which represent the cyclic voltammograms for the oxidation of $\mathrm{AO} 7\left(2.10^{-4} \mathrm{M}\right)$ at temperatures ranging from 20 to $60{ }^{\circ} \mathrm{C}$, respectively.

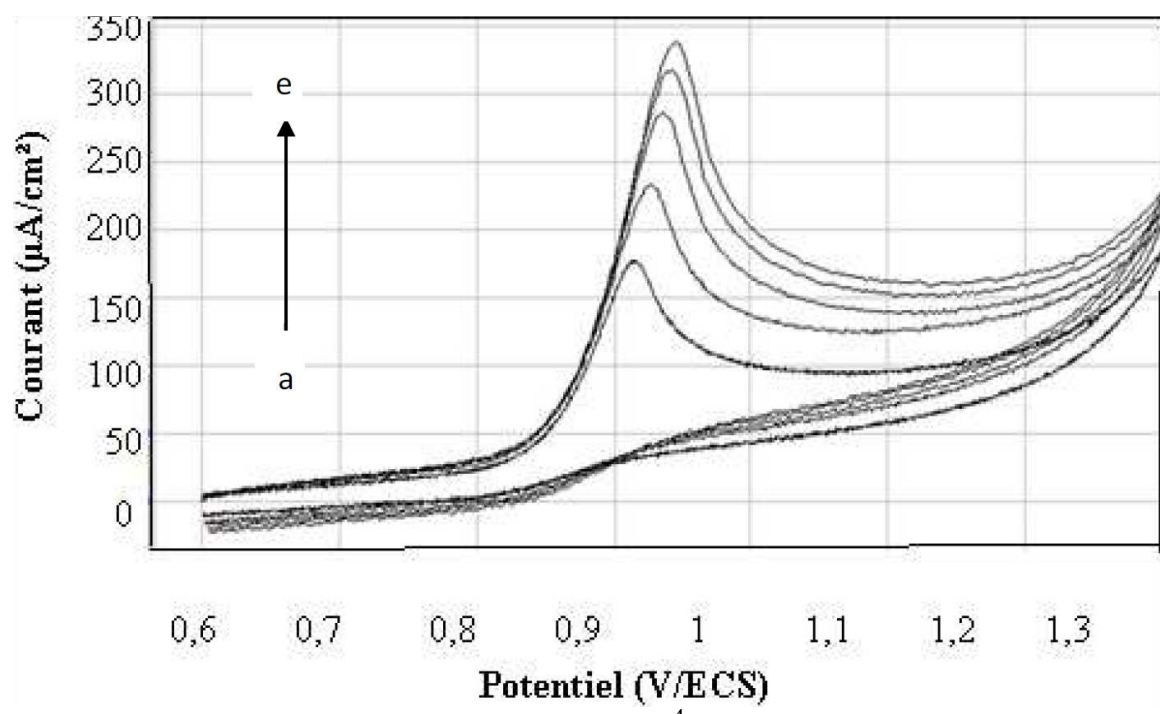

Figure 4. Cyclic voltammograms of AO7 $\left(2 \cdot 10^{-4} \mathrm{~mol} / \mathrm{L}\right)$ in DMSO with different scan rates: (a) $50 \mathrm{mV} / \mathrm{s}$, (b) $100 \mathrm{mV} / \mathrm{s}$, (c) $150 \mathrm{mV} / \mathrm{s}$; (d) $200 \mathrm{mv} / \mathrm{s}$; (e) $200 \mathrm{mV} / \mathrm{s}$.

Using DMSO (Fig. 3 -a) and water (Fig. 3 -b) the examination of Fig. 3 shows that, when the temperature increases, the current of the peak oxidation increases. In addition, the peak potential $\mathrm{E}_{\mathrm{pa}}$ shifts to the cathodic values.

On the other hand, the activation energy calculated using Arrhenius' law shows that the activation energy using DMSO $\left(\mathrm{E}_{\mathrm{a}}=9.8 \mathrm{~kJ} / \mathrm{mol}\right)$ is lower than that in aqueous solvent $(27.3 \mathrm{~kJ} / \mathrm{mol})$, which proves the easier oxidation of AO7 in DMSO solvent. For this reason, we hereafter propose to study the electrochemical oxidation of AO7 in DMSO.

\section{Voltammetries of AO7 in DMSO}

The effect of varying scan rates ranges between $50 \mathrm{mV} / \mathrm{s}$ and $250 \mathrm{mV} / \mathrm{s}$ was studied at the GCE in $\mathrm{H}_{2} \mathrm{SO}_{4} 0.5 \mathrm{M}$ electrolyte solution containing $2.10^{-4} \mathrm{M}$ AO7. With an increasing scan rate, the peak current increased, and also the peak potential shifted slightly with the anodic peak to positive, as shown in Fig.4.

From the plot of logarithm of the peak current against logarithm of scan rate, as shown in Fig. 5-a, the current (anodic) increases approximately in linear 
approach, as described by $\mathrm{R}=0.998$. In experimental, the slope has a value of $0.44 \approx 0.5$, which suggests that the process is purely diffusion controlled [38].

The relationships between $E_{\mathrm{p}}$ and $\log v$ in the cyclic voltammetry (Fig 5-b) could be expressed according to the following Laviron's equation (1) [39]:

$$
\mathrm{E}_{\mathrm{p}}=\mathrm{E}_{0}+\left[\frac{2.3 \mathrm{RT}}{\alpha \mathrm{nF}}\right] \log \left[\frac{\mathrm{RTk}}{\alpha \mathrm{nF}}\right]+\frac{2.3 \mathrm{RT}}{\alpha \mathrm{nF}} \log v
$$

where $\alpha$ is the electron transfer coefficient, $\mathrm{F}$ is the Faraday constant, $\mathrm{R}$ is the gas constant, $\mathrm{T}$ is the temperature, $\mathrm{k}$ is the standard rate constant of the surface reaction, $v$ is the scan rate, $\mathrm{n}$ is the electron transfer numbers and $\mathrm{E}_{0}$ is the formal potential. The value of $\alpha \cdot n$ was graphically determined from the slope of the line representing the path of the curve $E_{p}$ with $\log v$ and it is equal to 0.7 . The $\alpha$ value was determined from the relationship of Bardand Faulkner (Eq.2) [40] and it is equal to 0.6:

$$
\left|\mathrm{E}_{\mathrm{p}}-\mathrm{E}_{\mathrm{p} / 2}\right|=\frac{47.7}{\alpha}
$$

So, the number of electrons $(n)$ involved in the reaction is calculated to be 1.1 , which indicates that 1 electron is involved in the oxidation of AO7.

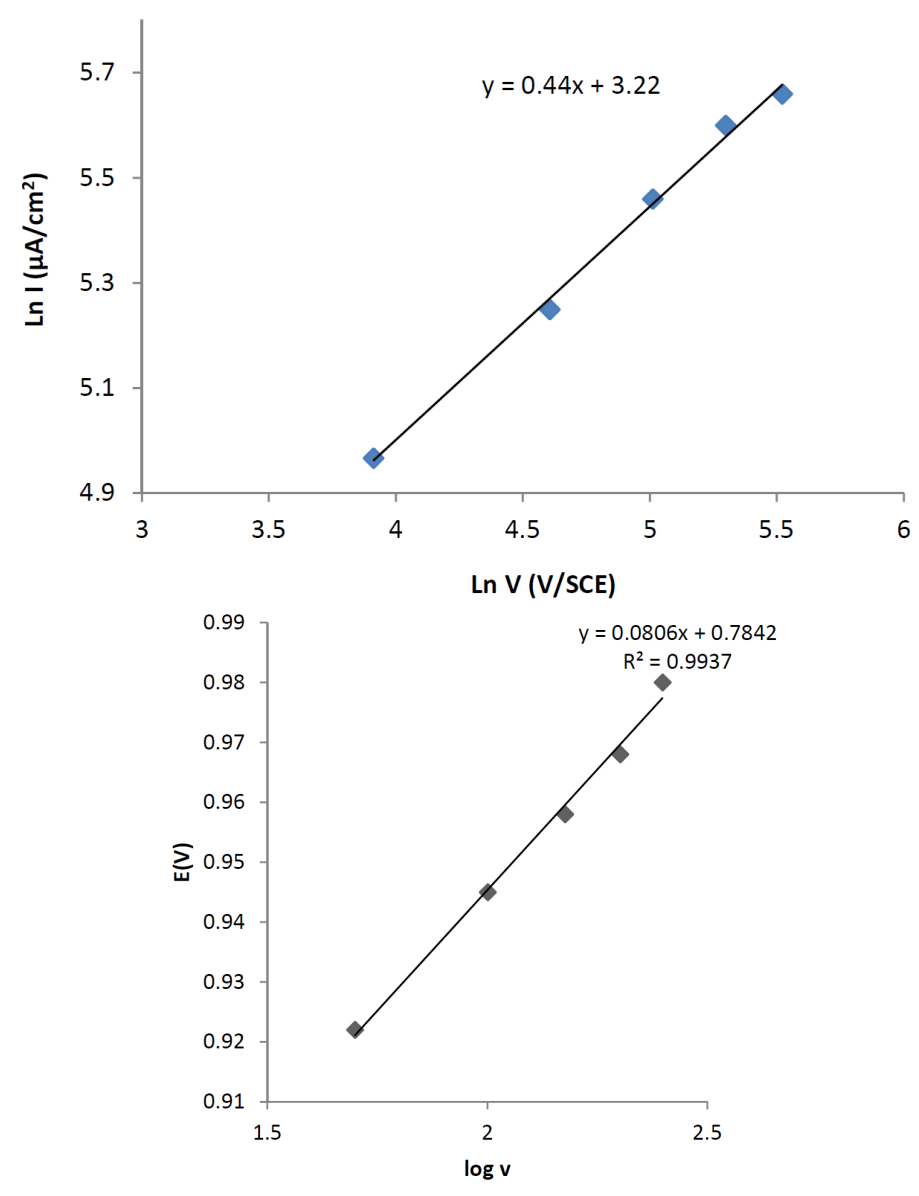

a)

b)

Figure 5. Plot of the $\log I_{p}$ against $\log$ scan rate (a) and plot of the peak potential against $\log$ scan rate (b), obtained for $2 \cdot 10^{-4} \mathrm{M} \mathrm{AO} 7$ in $0.5 \mathrm{M} \mathrm{H}_{2} \mathrm{SO}_{4}$ at the GCE with different scan rates from $50 \mathrm{mV} / \mathrm{s}$ to $250 \mathrm{mV} / \mathrm{s}$. 


\section{Effect of the concentration and detection limit}

In order to quantitatively detect $\mathrm{AO} 7$, the concentrations of this dye were varied from $0.04 \mathrm{mM}$ to $0.2 \mathrm{mM}$ in a $0.5 \mathrm{M}$ sulfuric acid solution. The oxidation peak current of $\mathrm{AO} 7$ on GCE is linearly proportional to its concentration (c) in a range from $0.04 \mathrm{mM}$ to $0.2 \mathrm{mM}$, with a correlation coefficient of 0.993 (Fig 6-a). High sensitivity responses of $45.09 \mu \mathrm{A} / \mathrm{mM}$ for the peak current are also obtained (Fig $6-b)$.

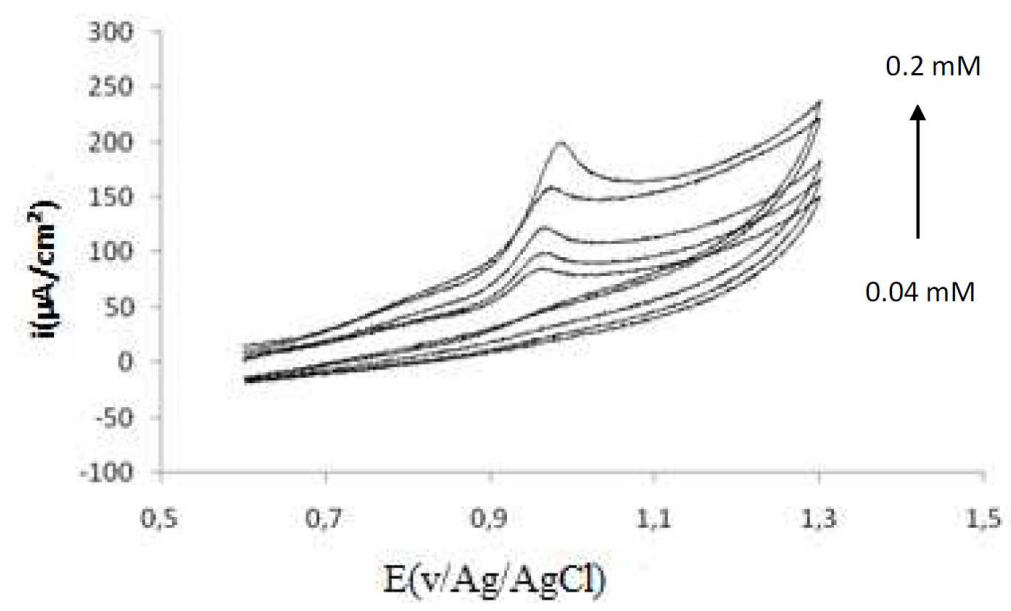

a)

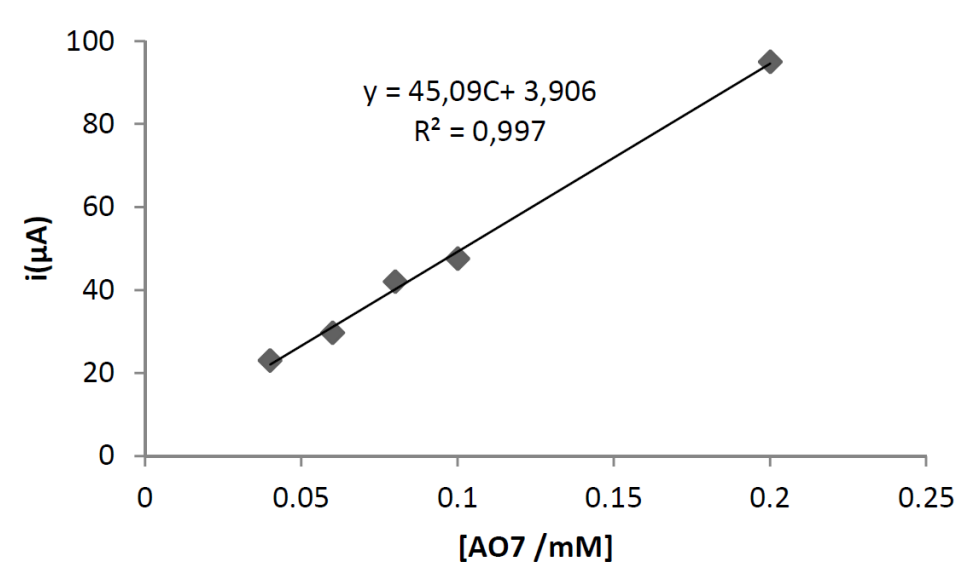

b)

Figure 6. a) Cyclic voltammetry response of $\mathrm{AO} 7$ with different concentrations of 0.04 $\mathrm{mM}-0.2 \mathrm{mM}$ at the GCE in $0.5 \mathrm{M} \mathrm{H}_{2} \mathrm{SO}_{4}$ with a scan rate of $100 \mathrm{mV} / \mathrm{s}$. b) Dependence of the peak current against concentration of $\mathrm{AO} 7$ ranges from $0.04 \mathrm{mM}$ to $0.2 \mathrm{mM}$.

Calibration plots bearing linear relationships for the oxidation peak current $\mathrm{I}_{\mathrm{p}}=$ $45.09 x+3.9$ showed an excellent correlation coefficient of 0.997. Based on the expression of $3 \sigma$ /slope (oxidation process), the limit of detection was estimated by gradually decreasing the concentration levels of AO7 with the detection limit of $6.6 \mu \mathrm{M}$ when using a scan rate of $100 \mathrm{mV} / \mathrm{s}$.

\section{Conclusions}

In this work, a simple, rapid, and sensitive electrochemical method was developed to determine AO7. The cyclic voltammetric studies of AO7 were performed in water, acetone (ACE) and dimethyl sulfoxide (DMSO). AO7 exhibits an irreversible one-electron transfer process in all of the investigated 
solvent media. The effect of the solvent medium on potential $\mathrm{E}$ was discussed in terms of its electron-donating power. Hence, the potential $\mathrm{E}$ values are significantly less anodic in strong electron-donating solvents such as DMSO, but tend to become more anodic in weaker electron-donating solvents such as ACE. The electrochemical parameters were calculated.

\section{References}

1. Martinez-Huitle CA, Brillas E. Appl Catal B-Environ. 2009;87:105.

2. Fernandes A, Morao A, Magrinho M, et al. Dyes Pigments 2004;61:287.

3. Dhir H, Agawal K, Sharma A, et al. Cancer Letter 1991;59: 9-18.

4. Park H, Kwon D-H, Rhee Y. J Opt Soc Am B. 2004;21:1250-1254 .

5. Jain R, Sharma N, Radhapyari K. J Appl Electrochem. 2009;39:577-82.

6. Yang D, Zhu L, Jiang X. J Electroanal Chem. 2010;640:17-22.

7. Jain R, Varshney S, Sikarwar S. Int J Environ Eng. 2009;1:95-105.

8. Jain R, Sharma N, Bhargava M. J Sci Ind Res. 2003;62:1138-44.

9. Nigovic B, Mandic Z, Simunic B, et al. J Pharm Biomed Anal. 2001;26:98794.

10. Radi AE, Nassef HM, El-Basiony A. Dyes Pigments 2013;99:924-9.

11. Airinei A, Rusu E, Dorohoi D. Spectrosc Lett. 2001;34:65.

12. Pielesz A, Wlochowicz A. Spectrochim Acta Part A. 2001;57;2637.

13. Snehalatha M, Ravikumar C, Joe IH, et al. Spectrochim Acta Part A. 2009;72:654.

14. Snehalatha M, Sekar N, Jayakumar VS, et al. Spectrochim Acta Part A. 2008;69:82.

15. Sullivan AG, Gaskell S. J Rapid Comm Mass Spectrom. 1997;11:803.

16. Sullivan AG, Garner R, Gaskell S. J. Rapid Comm Mass Spectrom. 1998;12:1207.

17. Gennaro MC, Gioannini E, Angelino S, et al. J Chromatogr Ser A. 1997;767:87.

18. Rafols C, Barcelo D. J Chromatogr Ser A. 1997;777:177.

19. Holcapek M, Jandera P, Prikryl J. Dyes Pigm. 1999;43:127.

20. Fuh MR, Chia KJ. Talanta. 2002;56:663.

21. Cano JM, Marín ML, Sánchez A, et al. J Chromatogr A. 2002;963:401-9.

22. Ertas E, Ozer H, Alasalvar C. Food Chem. 2007; 105:756.

23. Molder K, Kunnapas A, Herodes K, et al. J Chromatog Ser A. 2007;1160:227.

24. Tsierkezos NG. J Solution Chem. 2007;36:289-302.

25. Lai-Hao. Elektrokhimiya. 2010;46:1509-1513.

26. Chen M. Int J Electrochem Sci. 2014;9:847-855

27. Karaman Y. Dyes Pigments. 2014;106: 39-44.

28. Ryu HS, Ahn HJ, Kim KW, et al. J Power Sources. 2006;153:360.

29. Choi JW, Kim JK, Cheruvally G, et al. Electrochim Acta. 2007;52:2075.

30. Kim S, Jung Y, Park SJ. Electrochim Acta. 2007;52: 2116.

31. Merritt MV, Sawyer DT. Inorg Chem. 1970;9:211.

32. Martin RP, Sawyer DT. Inorg Chem. 1972;11:2644. 
33. Fujinaga T, Kuwamoto T, Okazaki S, et al. Bull Chem Soc Jpn. 1980;53:2851.

34. Sharp PR, Frank KG. Inorg Chem. 1985;24:1808-1813.

35. Casarin M, Ajo D, Granozzi G, et al. Inorg Chem. 1985;24:1241-1246.

36. Batterjee SM, Marzouk MI, Aazab ME, et al. Appl Organomet Chem. 2003;17:291-297.

37. Keita B, Bouaziz D, Nadjo LJ. Electrochem Soc. 1988;135:87-91.

38. Gosser DK. Cyclic voltammetry: simulation and analysis of reaction Mechanisms. New York: VCH; 1993.

39. Laviron E. J Electroanal Chem. 1979;101:19.

40. Bard AJ, Faulkner LR. Electrochemical methods: principles, methods et applications. Paris: Masson; 1983. 